\title{
Establishment of Evaluation Parameter System and Method of Weapon and Equipment Readiness
}

\author{
Liang $\mathrm{Ma}^{1 \mathrm{a}}$ and Jie $\mathrm{Jia}^{2 \mathrm{~b}}$ \\ ${ }^{1}$ Department of Surface Ship Command, Dalian Naval Academy, Dalian, 116018,China; \\ ${ }^{2}$ NO.3 student brigade, Army Logistics University of PLA,ChongQing,401331,China

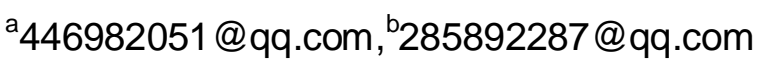

Keywords: Evaluation parameter system; Weapon and equipment readiness

\begin{abstract}
Equipment readiness evaluation index system is an important part of equipment readiness work. First introduces the basic concepts, then analyzes the equipment readiness evaluation index system of principles and objectives, finally around the organization and leadership, daily equipment readiness work, combat readiness level equipment, equipment readiness drills in four aspects, such as content, equipment readiness evaluation index system and method are discussed.
\end{abstract}

\section{Introduction}

Equipment readiness is an important part of military combat readiness, completes the equipment readiness work, improve the equipment level of combat readiness, is equipped with authorities at various levels and equipment support forces (unit) the important guarantee of performing functions ${ }^{[1]}$.

For the construction information army, win the information-based war, must strengthen the construction of army equipment readiness, standards and evaluation equipment readiness. Only by establishing appropriate and effective equipment readiness evaluation index system, to make the forces and equipment readiness check assessment to achieve standardization and scientization; Only scientific evaluation, can correctly guide the direction of the equipment readiness activities ${ }^{[2]}$.

Our different versions of the example and the explanation of dictionary for the word "readiness" expression is differ, but all contain the war or preparations for the war. Equipment readiness of this article is to point to our army equipment organs at all levels and equipment support forces (unit) to cope with the possibility of war or the military emergency preparation and alert and in peacetime. The equipment authority is explained equipment departments at various levels have different expression, but all contain the war or preparations for the war.

Equipment readiness of this article is to point to our army equipment organs at all levels and equipment support forces (unit) to cope with the possibility of war or the military emergency preparation and alert and in peacetime. Which equipment authority refers to equipment and commander of the departments at all levels, political department, logistics department, the department in charge of the relevant equipment; Equipment support forces (unit) refers to the headquarters, services and arms, military area commands and the force's active equipment support units[3]. Commander and departments, the political department, logistics department, the department in charge of the relevant equipment; Equipment support forces (unit) refers to the headquarters, services and arms, military area commands and the force's active equipment support units.

Equipment readiness evaluation refers to the standard, according to set inspection equipment readiness work to carry out the situation, the inspection equipment readiness work ability, evaluation process of equipment level of job of combat readiness. It includes evaluation subject, evaluation object, evaluation index, evaluation criteria and evaluation method of five elements. Evaluation main body is composed of equipment professional experts and superior equipment authority, when the self-assessment can also consists of equipment at the corresponding level authority personnel; Evaluation object is equipment readiness activities; Evaluation index is the scope of the object to the assessment implementation evaluation is important basis of evaluation, a 
quantitative index and qualitative index 2 class; Evaluation criteria is the basis of assessment, quantitative standard and the qualitative standard two points; Evaluation methods to evaluate the technical specifications is the concrete implementation, including quantitative qualitative analysis method, calculation method, or a combination of use[4].

\section{Goals and Principles}

Equipment evaluation index system of combat readiness, is used to check the equipment readiness work to carry out the situation, the inspection equipment readiness work level ruler, not for someone, a department, but rather to irm equipment of all kinds of forces organs at all levels and equipment support forces (unit) to design, therefore, it is a practical and operational systems engineering. The goal of the combat readiness index system is to equip it with the desired state of readiness. The requirements and expectations of equipment readiness are multifaceted, and these requirements and expectations are reflected in the goals, which form the overall objectives and objectives $^{[5]}$. The general goal is to equip combat readiness and response capabilities to provide reliable, rapid protection for operations and emergencies. The goal is to achieve the optimal state of the target. The following principles should be adhered to in the construction of the determination of the overall optimal level and the ability to accurately respond to the preparation of combat readiness.

One is objectivity. Equipment readiness assessment object is combat readiness work equipment, its subject, object is the objective, therefore, the design of evaluation index system should also be an objectivity, so as to achieve the true and accurate to evaluate equipment readiness.

The second is systemic. Systematicness is systematically determined by equipment, subject, object, and work itself. The armed forces are equipped with all levels of equipment and security forces (contingent), from the vertical, involving headquarters, various arms, military areas and troops; From a horizontal perspective, it is a large and crosswise organization system that involves the military commander, the political, logistics and equipment departments. The objects of war readiness include all kinds of weapons, ammunition, vehicles, machinery, equipment and fittings of the land, sea, air and artillery, and also a large weapon system. The combat readiness activities also involve material, spiritual and organizational aspects[6]. Equipment readiness assessment, therefore, not only consider a single factor, to work in equipment readiness system as a whole function as the starting point to adopt the principle of system evaluation, in order to comprehensively and objectively make reasonable evaluation.

The third is scientific. Equipment readiness work is composed of many tedious activity, involving all aspects of the equipment before and began the work, at ordinary times should be covered over armed combat readiness work all aspects of content, clear hierarchy and evaluation standard and reasonable index system, to the specific content of the assessment to a quantitative, on the content of the is not easy to quantify, adopt qualitative analysis, strive to comprehensive use mathematics, statistics, modeling and other modern research methods, focus on using modern tools and equipment such as computer, in order to improve the scientific, accuracy of the evaluation process and results.

The fourth is testability. Armed combat readiness assessment methods are to be accepted and maintained for a longer period of time, so it must be easy to do so. The range of assessment indicators should be appropriate, neither too cumbersome nor too small, which would not meet the requirements of a comprehensive assessment. Pay attention to the definition of index meaning, avoid misunderstanding and ambiguity. In addition, the means of examination and assessment should establish different operation methods according to different contents. Such as the party committee, governor, organs perform their duties according to situation and equipment readiness system implementation, daily equipment readiness work such as content of the assessment report can be used to listen to, ask situation, look at the site and find information way; An oral test or written test can be used for examination and assessment of equipment combat readiness knowledge and equipment combat readiness. An exercise method is used to check the ability of organization and command, the ability to change the level of combat readiness, and the quick response ability[7]. 
Five is the point. Equipment readiness assessment to seize the key global influence the equipment readiness work equipment war readiness plan, equipment, material, time limit ready conversion, according to the plan practice content set as key indicators, such as the one ticket veto; Give high weight to the main indexes reflecting main content; Indicators that reflect secondary content can ignore or retain fewer and give lower weights. Only when the key content and key indicators are properly assessed can the effectiveness of the assessment be ensured.

\section{Establish the Equipment War Readiness Assessment Index System}

\section{Establish indicators and standards}

Through a thorough research to the services unit, draw lessons from to absorb the grassroots units at ordinary times the introspection self checking index, proposed at the beginning of evaluation index system, and organization and equipment experts, professors and staff to discuss project, the general headquarters/departments, according to the general armaments department of equipment readiness work content, carries on the analysis, comparison and summary of common content, after repeated scrutiny and modify, determine the three-level index structure. On all levels of personnel duty, daily equipment readiness level equipment, equipment readiness exercise, such as main work content, set up the organization and leadership, daily equipment readiness work, combat readiness level equipment, equipment readiness exercise 4 first-level indicators. And then parse the content of the primary index respectively, set up 20 secondary indexes, including the party committee, the party branch organization leadership, army chief, armaments department (in) long, other equipment authority personnel, equipment support forces (unit) five indicators; Daily equipment readiness work includes equipment readiness education, combat readiness work research equipment, equipment readiness plan, equipment readiness on duty, equipment readiness report instruct, personnel and equipment goods and materials management, equipment readiness construction of facilities, equipment readiness information construction, equipment mobilization preparation, equipment support ten indexes in battlefield construction; The level combat readiness equipment includes the combat readiness conversion and the force conversion guarantee work 2 indicators; Equipped with combat readiness exercises, including the practice system, the organization and implementation, the exercise effect 3 indicators. Finally, the secondary index is further analyzed, and 58 three-level indexes are identified, and the three-level index is also the standard[8].

\section{Determine the index weight set}

Because each work is equipped with a priority, it is the importance of the evaluation indicators to the equipment readiness. In order to accurately, reasonably and intuitively express the importance of various evaluation indexes in equipment preparation, weights must be given to each index in the index system. The index system can be used to evaluate activities only when the weight of each index is given to the index system.

In order to facilitate calculation and comparison, the weights of indicators are given as follows: first, the weight of the index is a positive value not greater than 1 . The second is the sum of the weight of the subordinate indicators belonging to a certain index is 1 .

On the set of weights, through the organization of military equipment expert practitioners, headquarters department chief, forces of three kinds of personnel team, develop a collective argument, according to the important degree of each index in the system setting, therefore, set up three levels of weight. The primary weight is the important degree of each factor in the equipment combat readiness. The secondary weight is the important degree of the secondary index each factor in the corresponding primary index. The three-level weight is the important degree of each factor in the corresponding secondary index.

Is important to emphasize, standards, and weights are only has relative stability, it will be as the change of the military strategy, and the corresponding changes, requirements for timely correction, therefore, necessary to organize experts to set up the index system. 


\section{Equipment Readiness Assessment Method}

The methods of evaluation include fuzzy comprehensive evaluation, data envelopment analysis and evaluation, artificial neural network evaluation and grey comprehensive evaluation. This paper adopts fuzzy comprehensive evaluation method and variable weight fuzzy comprehensive evaluation method.

Fuzzy multilevel comprehensive evaluation method of the basic idea is: first, to the lowest level of the assessment factors of fuzzy comprehensive evaluation according to branch, and then to the hierarchical fuzzy comprehensive evaluation of fuzzy comprehensive evaluation set as a hierarchical fuzzy comprehensive evaluation of single factor evaluation, one layer upward, in turn, make a comprehensive evaluation, until the highest overall fuzzy comprehensive evaluation results are obtained. For the sake of simplicity, the index (see table 1) is used to evaluate the performance of the loading department (see table 1) for example, and a fuzzy comprehensive evaluation model is established.

Table 1 The equipment minister performs the duty indicators and weights

\begin{tabular}{|l|l|}
\hline index & The weight \\
\hline $\begin{array}{l}\text { Implement the relevant laws and } \\
\text { regulations }\end{array}$ & 0.3 \\
\hline Armed with combat readiness & 0.2 \\
\hline $\begin{array}{l}\text { Be familiar with equipment preparation } \\
\text { plan }\end{array}$ & 0.3 \\
\hline $\begin{array}{l}\text { The organization completed the combat } \\
\text { readiness task }\end{array}$ & 0.2 \\
\hline
\end{tabular}

A collection of elements Evaluation factor set $U=\left\{u_{1}, u_{2}, u_{3}, u_{4}\right\}$ of the object being judged. According to the needs of the troops, the evaluation of equipment readiness is a three-level assessment, namely, excellent, qualified and unqualified. For the project of quantitative assessment, the maximum score of each inspection item is 100, the above 90 is excellent, 60 points to 90 are qualified, and 60 below are not qualified. One of the key indicators was not qualified, and the overall assessment was not qualified.

\section{Conclusion}

The evaluation index system is the basis for evaluation, and the system of equipment readiness assessment must be able to objectively and comprehensively reflect the actual situation of the evaluation object. Due to the limited rationality of the framers and the development of equipment combat readiness, the establishment of the index system of equipment combat readiness assessment is a continuous improvement process. For the evaluation method, this paper considers that the multi-level fuzzy comprehensive evaluation after the adoption of variable rights can be more objective, more accurate and more scientific to reflect the actual situation.

\section{References}

[1] K. T. Atanassov. Intuitionistic fuzzy sets [J]. Fuzzy Sets and Systems, 1986, 20: 87-96.

[2] W. L. Hung, M. S. Yang. Similarity measures of intuitionistic fuzzy sets based on Hausdorff distance [J]. Pattern Recognition Letters, 2004, 25: 1063-1611.

[3] L. A. Zadeh. Fuzzy sets [J]. Inform. And Control, 1965, 8: 338-353.

[4] S. K. De, R. Biswas, A. R. Roy. Some operations on intuitionistic fuzzy sets [J]. Fuzzy Sets and Systems 2000, 114: 477-484.

[5] S. M. Chen, J. M. Tan. Handling multicriteria fuzzy decision-making problems based on vague set theory [J]. Fuzzy Sets and Systems, 1994, 67: 163-172.

[6] D. H. Hong, C. H. Choi. Multicriteria fuzzy decision-making problems based on vague set 
theory [J]. Fuzzy Sets and Systems, 2000, 114: 103-113.

[7] Yager. R. R. On ordered weighted averaging aggregation operators in multicriteria decision making [J]. IEEE Transactions on Systems, Man, and Cybernetics, 1988, 18: 183-190.

[8] Xu. Z. S, Da. Q .L. The ordered weighted geometric averaging operators [J]. International Journal of Intelligent Systems, 2002, 17: 709-716. 